CONSEQUENCES OF PROPOSED CHANGES TO CLEAN WATER ACT THERMAL DISCHARGE REQUIREMENTS

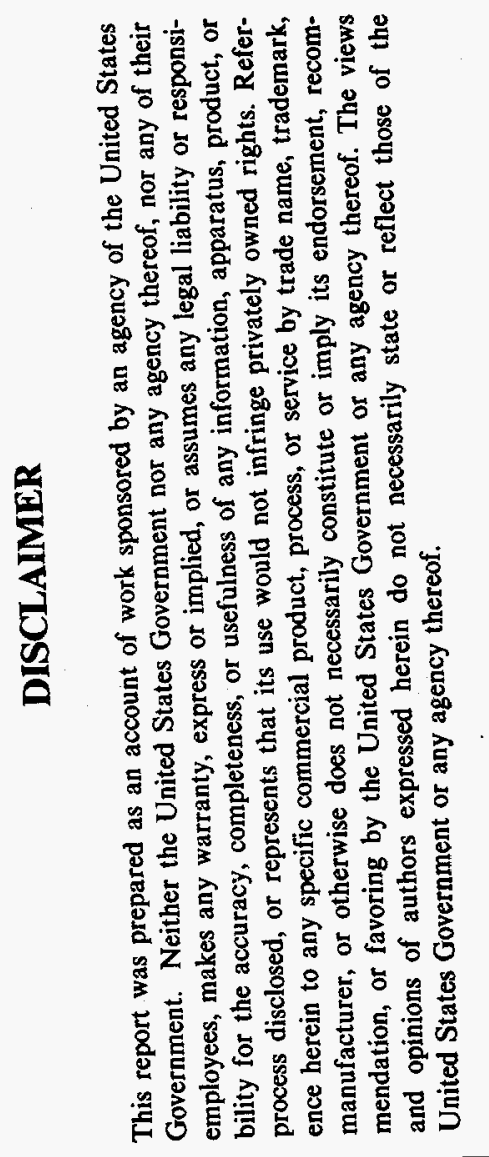

\author{
prepared by \\ John A. Veil \\ Argonne National Laboratory \\ Washington, DC \\ and \\ David O. Moses \\ U.S. Department of Energy \\ Washington, DC
}

RECFIVFO

JAN 301995

OSTI

to be presented at 1995 EPRI International Clean Water Conference

La Jolla, CA

November 28, 1995 


\title{
CONSEQUENCES OF PROPOSED CHANGES TO CLEAN WATER ACT THERMAL DISCHARGE REQUIREMENTS
}

\author{
John A. Veil \\ Argonne National Laboratory \\ 955 L'Enfant Plaza, SW, Suite 6000 \\ Washington, DC 20024 \\ and \\ David O. Moses \\ U.S. Department of Energy, PO-62 \\ Washington, DC 20585
}

\begin{abstract}
This paper summarizes three studies that examined the economic and environmental impact on the power industry of: a) limiting thermal mixing zones to 1,000 feet, and b) eliminating the Clean Water Act (CWA) §316(a) variance. Both of these proposed changes were included in S. 1081, a 1991 Senate bill to reauthorize the CWA. The bill would not have provided for grandfathering plants already using the variance or mixing zones larger than 1000 feet. Each of the two changes to the existing thermal discharge requirements were independently evaluated. Power companies were asked what they would do if these two changes were imposed. Most plants affected by the proposed changes would retrofit cooling towers and some would retrofit diffusers. Assuming that all affected plants would proportionally follow the same options as the surveyed plants, the estimated capital cost of retrofitting cooling towers or diffusers at all affected plants ranges from $\$ 21.4$ to 24.4 billion. Both cooling towers and diffusers exert a $1 \%$ $5.8 \%$ energy penalty on a plant's output. Consequently, the power companies must generate additional power if they install those technologies. The estimated cost of the additional power ranges from $\$ 10$ to 18.4 billion over 20 years. Generation of the extra power would emit over 8 million tons per year of additional carbon dioxide. Operation of the new cooling towers would cause more than 1.5 million gallons per minute of additional evaporation. Neither the restricted mixing zone size nor the elimination of the $\$ 316$ (a) variance was adopted into law. More recent proposed changes to the Clean Water Act have not included either of these provisions, but in the future, other Congresses might attempt to reintroduce these types of changes.
\end{abstract}

\section{Introduction}

\section{Background}

In its first session, the 104th Congress has considered reauthorizing or amending many of the major environmental statutes. Generally the proposed changes would lead to less stringent environmental controls. One example is H.R. 961, a Clean Water Act (CWA) reauthorization bill passed by the House 
in May 1995 that proposes many changes to water pollution control requirements. Several sections of H.R. 961 that are relevant to electric power industry thermal discharges are summarized in a later section of this paper.

This current trend toward easing environmental controls has not been the norm in recent years, however. In the 102nd Congress (1991-1992), the Senate considered and widely debated S. 1081, a CWA reauthorization bill that would have significantly tightened water pollution controls. Of particular interest to the electric power industry were two proposed changes to the existing thermal discharge requirements. The bill proposed: a) limiting mixing zones, including thermal mixing zones, to 1000 feet from the point of discharge, and b) deleting $\$ 316(\mathrm{a})$ from the CWA, which would take away the valuable $\$ 316(\mathrm{a})$ thermal variance provision. No grandfathering provisions were included for facilities currently using a $\$ 316$ (a) variance or a mixing zone larger than 1000 feet. Both of these changes were thought to have large economic consequences for the electric power industry.

Although S. 1081 was not passed by the Senate, it is uncertain what changes, if any, Congress will make regarding thermal discharges. While it is unlikely that the 104th Congress will propose new stricter thermal discharge requirements, future Congresses, with different political makeups and interests, might revisit stricter thermal discharge requirements, such as those proposed in S. 1081. This paper summarizes three reports by Argonne National Laboratory that assess the economic and environmental impacts that such legislative changes could have on the power industry, if such changes were enacted. Two of the reports estimate the impacts of deleting the $\$ 316(\mathrm{a})$ variance from the $\mathrm{CWA}^{1,2}$ and the third report estimates the impacts of limiting thermal mixing zones to 1000 feet $^{3}$.

\section{Use of Cooling Water in Power Generation}

Water is used in many industrial applications for cooling machinery or for condensing steam. The largest industrial user of cooling water is the steam electric power industry. Most power plants use either oncethrough cooling or closed-cycle cooling. Once-through cooling systems withdraw large volumes of water from a river, lake, estuary, or ocean, pump the water through the condenser, and return it to the same or a nearby body of water. Closed-cycle cooling systems ${ }^{a}$ rely on a cooling tower and basin, cooling pond, or cooling lake. Water is withdrawn from the cooling tower basin, pond, or lake; pumped to the condenser; and then returned to the basin, pond, or lake.

The majority of the generating units that would be affected by the proposed changes to the thermal discharge requirements presently use once-through cooling systems. In 1991, the steam electric generating capacity in the United States totaled 568,871 megawatts (MW). Generating units with $250,466 \mathrm{MW}(44 \%)$ of this capacity used once-through cooling ${ }^{4}$.

\section{Existing Thermal Discharge Requirements}

The temperature of the discharged cooling water is typically limited by state thermal water quality standards. Some states have established site-specific water quality standards for temperature or have

a In this report, the term "closed-cycle cooling" means "cooling tower" unless some other type of closed-cycle cooling system is specifically mentioned. 
otherwise established water quality standards that take into account existing power plant discharges. There are two mechanisms that can allow adjustments to the thermal limits. Either or both of these mechanisms can be used at a power plant.

First, thermal mixing zones may be allowed, which provide an opportunity for dilution and in-stream cooling of heated discharges prior to measuring compliance with the thermal standards. Each state has different mixing zone size and shape criteria. Most once-through cooling discharges rely on thermal mixing zones. Second, $\$ 316(\mathrm{a})$ of the CWA allows the states or EPA to establish alternative thermal limits if the discharger can demonstrate that the otherwise applicable thermal effluent limits are more stringent than necessary to protect the organisms in and on the receiving water body, and that other, less stringent effluent limitations would protect those organisms. About $75 \%$ of the domestic generating capacity using once-through cooling systems operate under $\$ 316(a)$ variances ${ }^{4}$.

\section{Methodology}

Information was collected from a sample of power plants in different parts of the country that use oncethrough cooling. In separate surveys, selected power companies were asked what each plant would do: a) if it had to meet thermal limits within a 1000 -foot mixing zone, or b) if the $\$ 316$ (a) variance were no longer available. The power companies also were asked to provide cost estimates, when available, for constructing new facilities and equipment to meet the changed requirements. While geographical diversity was sought and achieved, this was not a statistically random sample of the steam electric power industry. Therefore, the results of this study may not be representative of the entire industry. On the other hand, there is no reason to believe that the cost estimates developed in this manner are not a reasonably good gauge of the actual costs to the industry. Responses were received from 13 companies representing 79 plants for the mixing zone study and from 14 companies representing 38 plants for the $\S 316($ a) variance study.

The data from the power companies were used to develop capital cost rates in terms of dollars per kilowatt $(\$ / \mathrm{kW})^{1,3}$. To estimate national capital costs, these cost rates were multiplied by the national affected capacity in megawatts (MW). The affected capacity was assumed to consist of those generating units that were currently using a $\$ 316$ (a) variance and those generating units that would be unable to meet limits based on a 1000-foot mixing zone. This methodology assumes that the limited sample of plants providing data is proportionately representative of the nationwide power industry.

\section{Results}

\section{\$316(a) Variance Study - Capital Costs}

Approximately 680 units would be affected if the $\$ 316($ a) variance were lost. These units have a combined generating capacity of roughly $189,000 \mathrm{MW}$, which represents $33 \%$ of the total steam electric generating capacity in the United States. Of those $189,000 \mathrm{MW}$, approximately $43,000 \mathrm{MW}$ are attributable to nuclear plants and approximately $146,000 \mathrm{MW}$ are attributable to fossil-fuel plants 5 There are a variety of potential alternatives for each affected plant, including: 
seeking relaxed thermal discharge requirements from the state regulatory agency; retiring a plant; operating only seasonally or at a lower output; moving the discharge structure to deeper water; adding a diffuser; and retrofitting ${ }^{\mathrm{b}}$ once-through cooling systems with cooling lakes or ponds or cooling towers.

The 14 power companies that provided information reported that they would retrofit cooling towers at nearly all of their 38 plants now operating under $\$ 316(\mathrm{a})$ variances. Figures 1 and 2 show the capital cost estimates provided by the power companies to retrofit cooling towers as a function of power production capacity. Because costs for construction at a nuclear plant are nearly always higher than those for construction at a fossil-fuel plant, data are presented separately for the two fuel types. The reported cost rates ( $\$ / \mathrm{kW}$ scaled to 1992 dollars) for fossil-fuel plants range from $\$ 32 / \mathrm{kW}$ to $\$ 346 / \mathrm{kW}$, with an average of $\$ 108 / \mathrm{kW}$ for 31 plants. The cost rates for nuclear plants range from $\$ 102 / \mathrm{kW}$ to $\$ 234 / \mathrm{kW}$, with an average of $\$ 171 / \mathrm{kW}$ for 7 plants ${ }^{1}$. Linear regression analysis was performed on the data. The resulting regression equations and correlation coefficients (r) are shown below.

$$
\begin{array}{lll}
\text { fossil-fuel plants } & \mathrm{y}=0.105 \mathrm{x}+2.2 & \mathrm{r}=0.77 \\
\text { nuclear plants } & \mathrm{y}=0.151 \mathrm{x}+31.4 & \mathrm{r}=0.53
\end{array}
$$

where $y=$ millions of 1992 dollars and $\mathrm{x}=\mathrm{MW}$

Lines representing these two equations are plotted on Figures 1 and 2 . The regression line for fossil-fuel plants fits nicely and is statistically very significant (probability $<0.01$ ). On the other hand, the regression line for nuclear plants does not represent the data set precisely. It is not statistically significant (probability $=0.125){ }^{c}$

National cooling tower retrofit costs were estimated by multiplying the appropriate cost rates by the affected capacity (146,000 MW for fossil-fuel plants and 43,000 MW for nuclear plants). For fossil-fuel plants, both the average fossil-fuel cost rate $(\$ 108 / \mathrm{kW})$ and the slope of the fossil-fuel regression line $(\$ 105 / \mathrm{kW})$ were used. Since the slope of the regression line for nuclear plants is not a reliable indicator of the data set, two other approaches -- the average nuclear cost rate $(\$ 171 / \mathrm{kW})$ and the median nuclear cost rate $(\$ 201 / \mathrm{kW})$-- were used to develop the national retrofit cost for nuclear plants.

The results of this analysis show that if $\$ 316(a)$ of the CWA were eliminated and all plants currently operating under $\$ 316$ (a) variances were retrofitted with cooling towers, the estimated national capital cost would range from $\$ 15.3$ billion to $\$ 15.8$ billion for fossil-fuel plants and from $\$ 7.4$ billion to $\$ 8.6$ billion for nuclear plants. The combined total ranges from $\$ 22.7$ billion to $\$ 24.4$ billion in 1992 dollars ${ }^{1}$. A similar but separate study, using a different methodology, estimated the capital cost to

b Retrofitting means modifying the existing cooling system and installing additional equipment. This may involve major construction and rerouting of piping.

- These probabilities represent the probability that the hypothesis (in this case, that the regression equation accurately expresses the distribution of data points) is incorrect. Generally, a probability $\leq 0.05$ is considered significant (the hypothesis is accepted), and a probability $<0.01$ is very significant. 


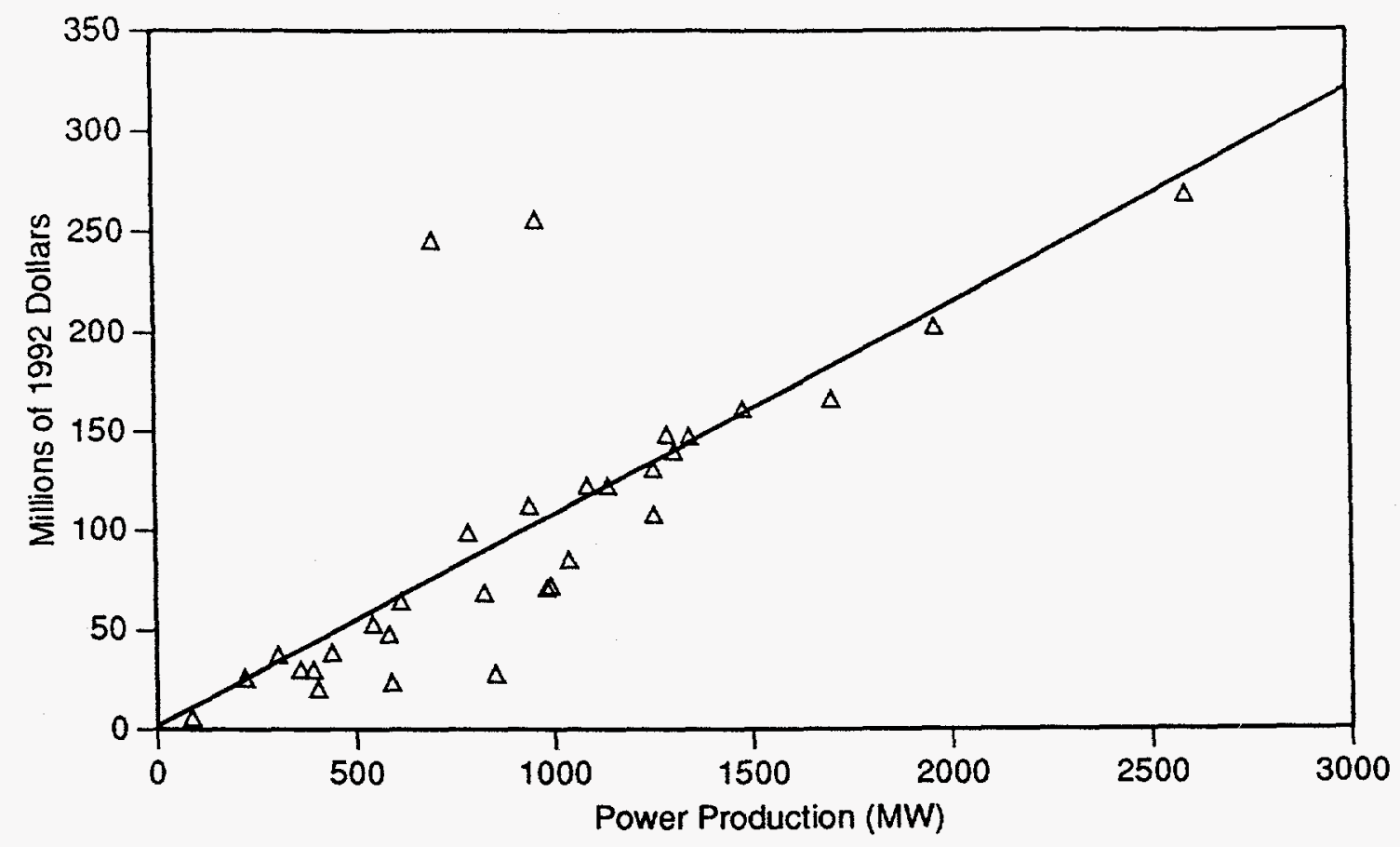

Figure 1 (from reference (1))

Capital Cost to Retrofit Fossil-Fuel Units with Cooling Towers

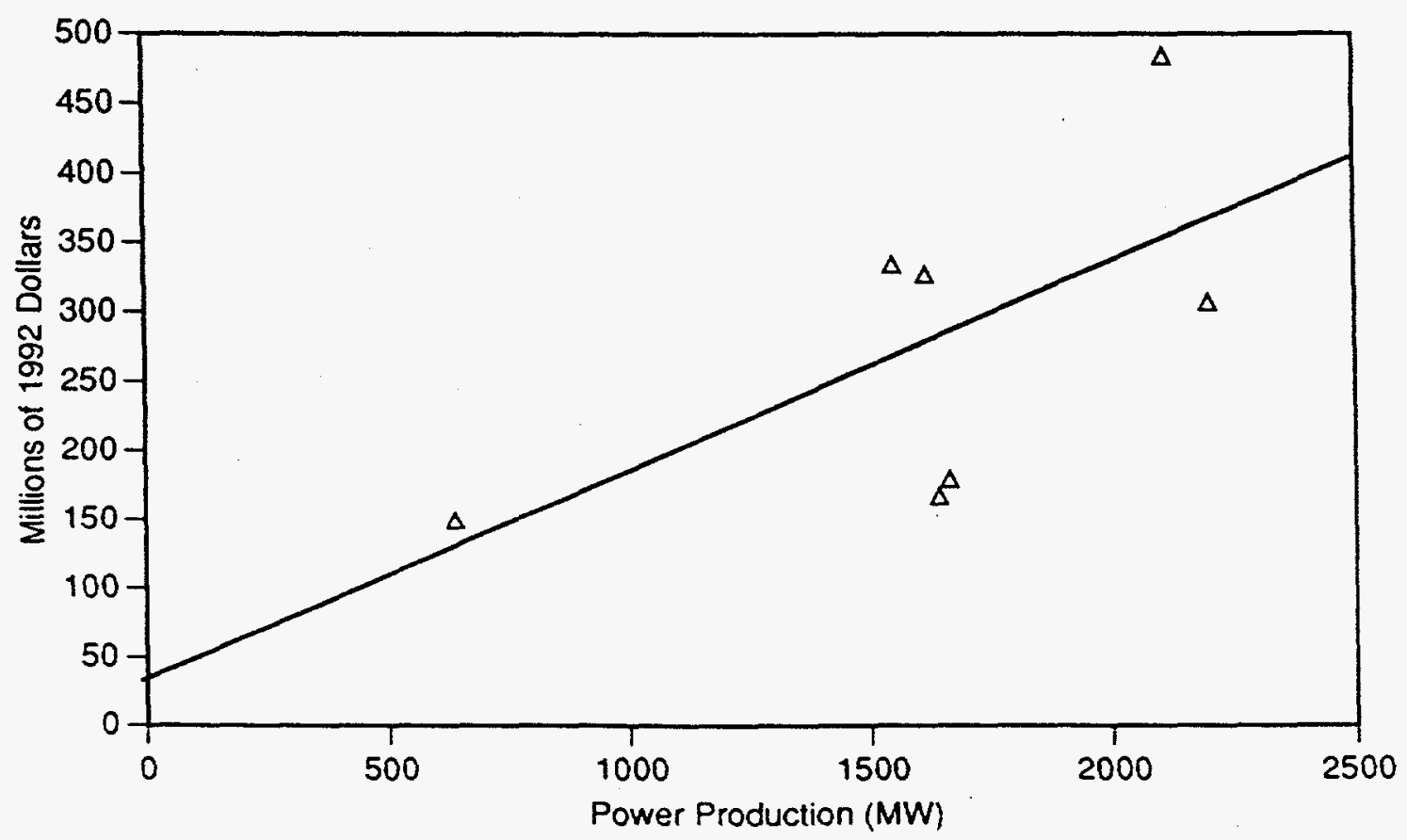

Figure 2 (from reference (1))

Capital Cost to Retrofit Nuclear Units with Cooling Towers 
the power industry of losing the $\$ 316$ (a) variance at $\$ 28.9$ billion in 1992 dollars ${ }^{5}$. The estimate from reference 5 is based on two hypothetical plants, one fossil-fuel and one nuclear, with the costs scaled up to all affected plants. The relatively close agreement of the two estimates using mostly independent methodologies suggests that the estimates are at least in the right order of magnitude.

\section{Mixing Zone Study - Capital Costs}

About $44 \%(250,466 \mathrm{MW})$ of the nation's power capacity is attributable to plants using once-through cooling systems, with $85 \%$ of that amount being at fossil-fuel plants and $15 \%$ being at nuclear plants ${ }^{4}$. The data collected from the 13 power companies indicate that 24 of the 79 plants for which data were provided may already be able to meet thermal standards within a 1,000-foot mixing zone. These plants represent $20,085 \mathrm{MW}$ of capacity, which is $26 \%$ of the total capacity reported in the study (78,049 $\mathrm{MW})^{3}$. However, four of the plants are located in Wisconsin, which at the time reference (3) was published did not have any thermal water quality standards. Therefore, these four plants are reported as being able to meet thermal standards within a 1,000-foot mixing zone. Wisconsin was considering establishing a thermal standard, with $89^{\circ} \mathrm{F}$ being the likely standard. None of these four plants could meet an $89^{\circ} \mathrm{F}$ standard within a 1,000-foot mixing zone $e^{3}$. The cost estimates presented in this paper do not include any retrofit costs for the four Wisconsin plants, although some future costs are likely.

The remaining 58 plants, ${ }^{d}$ representing $57,964 \mathrm{MW}$ of capacity $(74 \%$ of the total capacity evaluated in reference (3)), would not be able to meet thermal standards within a 1,000-foot mixing zone and would have to find an alternative mode of operation ${ }^{3}$. The available alternatives are the same as those discussed in the previous section. Operators of these 58 plants selected primarily two alternatives for compliance - cooling towers and diffusers (mechanical devices added to the end of discharge pipes to promote rapid mixing.) Diffusers would be added at six plants, cooling towers at 39 plants, and both diffusers and cooling towers at eight other plants. At two plants, helper towers (towers used to supplement once-through cooling systems) would be converted to full closed-cycle cooling. One company said it would consider either cooling towers or spray systems to enhance evaporation at three of its plants. One plant would be retired, and new replacement generating capacity would be constructed elsewhere. Several companies said that they would first try to have the state regulatory agency relax thermal standards, but they were not optimistic about the success of such a request. To simplify calculations, reference (3) combines all sample data alternatives involving retrofitting cooling towers (adding cooling towers or a spray system, converting helper towers to full-time closed-cycle cooling, or adding cooling towers and diffusers) with the one plant that would be retired into a single category (52 plants). The six plants using just diffusers constitute a second category.

The cooling tower cost rates used to calculate a national cost estimate are the higher end of the ranges from reference (3) -- $\$ 108 / \mathrm{kW}$ for fossil-fuel plants and $\$ 201 / \mathrm{kW}$ for nuclear plants. For diffusers, the

The total of 24 plants meeting the mixing zone and 58 plants not meeting the mixing zone adds to 82 rather than 79 plants. Three of the plants have one set of units that can meet the mixing zone and a different set of units that cannot meet the mixing zone. Those plants have been counted in both categories.

- The cost of retiring a plant and building new generating capacity greatly exceeds the cost of adding a cooling tower. In this case, the cost of installing a cooling tower is used rather than the full cost of building new generating capacity to keep the plant in the data set, and to make the final cost estimate more conservative. 
capital cost rates from reference (6) were modified to equal $\$ 43 / \mathrm{kW}$ for fossil fuel plants and $\$ 59 / \mathrm{kW}$ for nuclear plants ${ }^{3}$.

Table 1 shows the selected alternatives, the percentage of capacity (based on the sample data for this study) anticipated to use each alternative, the estimated capacity (in MW) nationwide that would use each alternative, the cost rates, and the total capital costs. The estimated national capital cost for retrofitting plants that cannot meet thermal standards within a 1,000 -foot mixing zone is up to $\$ 21.4$ billion.

Table 1

Calculation of National Cost Estimate (from reference (3))

\begin{tabular}{|c|c|c|c|c|}
\hline Selected Alternative & $\begin{array}{c}\text { Percentage } \\
\text { of Capacity } \\
\text { Using } \\
\text { Alternative* }\end{array}$ & $\begin{array}{c}\text { Affected } \\
\text { Capacity } \\
\text { Using } \\
\text { Alternative } \\
\text { (MW) }\end{array}$ & $\begin{array}{c}\text { Cost } \\
\text { Rate } \\
(\$ / \mathbf{k W})\end{array}$ & $\begin{array}{l}\text { Total Cost } \\
\text { (million \$) }\end{array}$ \\
\hline \multicolumn{5}{|l|}{ Diffuser } \\
\hline Fossil-fuel plants & 5 & 12,523 & 43 & 538 \\
\hline Nuclear plants & 1 & 2,504 & 59 & 148 \\
\hline \multicolumn{5}{|l|}{ Cooling towers } \\
\hline $\begin{array}{l}\text { Fossil-fuel plants } \\
\text { (mechanical-draft } \\
\text { towers) }\end{array}$ & 58 & 145,270 & 108 & 15,690 \\
\hline $\begin{array}{l}\text { Nuclear plants } \\
\text { (natural-draft towers) }\end{array}$ & 10 & 25,047 & 201 & 5,034 \\
\hline No changes needed & 26 & 65,121 & N/A & 0 \\
\hline Total & 100 & 250,466 & N/A & 21,410 \\
\hline
\end{tabular}

\section{Costs Associated with the Energy Penalty}

Retrofitting cooling towers or diffusers to existing power plants results in a reduction of plant output known as the energy penalty. The energy penalty is caused by increases in turbine back pressure that result in less efficient power generation, additional power requirements for pumping recycled water to the top of a natural-draft cooling tower or operating the fans at a mechanical draft cooling tower, and increased pump head requirements due to the restricted flow through a diffuser. Power companies have several options for dealing with the energy penalty. They can operate the plant at lower net power output, or in some cases, they can run it more frequently or at a higher temperature. The latter option 
requires that additional fuel be burned to maintain output. In either case, there is an energy cost associated with the retrofitting of cooling towers.

Cooling towers result in an energy penalty for fossil-fuel plants ranging from 1.1 to $4.6 \%$, with most of the data falling between 1.5 and $2.5 \%$. The cooling tower energy penalty for nuclear plants ranges from 1.0 and $5.8 \%$, with the selected data falling between 2 to $3 \%$. The energy penalty from diffusers is $0.02 \%$ for fossil-fuel plants and $0.028 \%$ for nuclear plants ${ }^{6}$.

The cost of compensating for the energy penalty has two components - the cost of generating replacement energy and the capital cost of building new generating capacity. The replacement energy cost is a function of the cost per kilowatt-hour, historical capacity factors, and the percent energy penalty. Table 2 summarizes the cost for replacement energy from references (2) and (3). Annual energy costs range from $\$ 370$ million to 670 million. The levelized, 20-year costs assume zero real escalation in fuel and variable operating and maintenance costs, a discount rate of $10.5 \%$, and an annual inflation rate of $4 \%$, resulting in a 20 -year energy cost ranging from $\$ 10$ billion to 18.4 billion.

Table 2

Nationwide Generation Capacity to Be Replaced Due to Energy Penalty and Associated Energy and Capital Costs (based on references (2) and (3))

\begin{tabular}{lllll} 
Category & $\begin{array}{l}\text { Replacement } \\
\text { Capacity } \\
\text { Needed }(\mathbf{M W})\end{array}$ & $\begin{array}{l}\text { Annual Energy } \\
\text { Cost } \\
(\mathbf{\$} \text { million) }\end{array}$ & $\begin{array}{l}\text { Levelized Energy } \\
\text { Cost for 20 Years } \\
\text { (\$ billion) }\end{array}$ & $\begin{array}{l}\text { Capital Cost for } \\
\text { Replacement } \\
\text { Capacity } \\
\text { (\$ billion) }\end{array}$ \\
\hline $\begin{array}{l}\text { Loss of } \\
\$ 316(\mathrm{a})\end{array}$ & $3050-4940$ & $420-670$ & $11.4-18.4$ & $1.4-5.3$ \\
$\begin{array}{l}\text { Variance } \\
\text { 1000' Mixing }\end{array}$ & $2700-4400$ & $370-590$ & $10-16.2$ & $1.2-4.8$ \\
Zone & & & &
\end{tabular}

The capital cost is determined on a utility-specific basis considering existing reserve margins, construction schedules for planned facilities, fuel prices, load projections, and the availability and cost of power purchases from other systems. To account for these capital cost issues, reference (2) used a range of replacement capacity costs -- $\$ 450 / \mathrm{kW}$ for a $50-\mathrm{MW}$ combustion turbine unit to $\$ 1080 / \mathrm{kW}$ for upgrading a $500-\mathrm{MW}$ coal unit to $600 \mathrm{MW}^{7,8}$. Table 2 summarizes the energy penalty capital costs estimated in references (2) and (3). The capital costs for replacement capacity range from $\$ 1.2$ billion to 5.3 billion.

f The percentage of power required to compensate for the energy penalty is relatively small. Some utilities would utilize reserves in their own system or purchase power from other systems. However, if the proposed changes were applied nationwide, the overall energy demand to compensate for the energy penalty would necessitate construction of new generating capacity. 


\section{Environmental Impacts}

Retrofitting cooling towers and diffusers at existing plants using once-through cooling would create secondary environmental impacts. For example, generating additional power to meet the energy penalty would increase carbon dioxide emissions by an estimated 8.2 million tons per year for plants restricted to a 1000 -foot mixing zone and 9 million tons per year for plants losing the $\$ 316$ (a) variance ${ }^{2,3}$. Although estimates for other airborne pollutants were not generated, substantial quantities of $\mathrm{SO}_{\mathrm{x}}$ and $\mathrm{NO}_{\mathrm{x}}$ would also be released. Construction of new generating units to meet the additional capacity required by the energy penalty would cause changes in land use, runoff characteristics, and wildlife habitat.

Conversion from once-through cooling systems to cooling towers would result in increased evaporation of about 2.6 million gallons per minute for plants not meeting the mixing zone limits and 1.5-2.8 million gallons per minute for plants losing the variance ${ }^{2,3}$. Other potential impacts from cooling towers include cooling tower drift (fog plumes and downwind deposition of water droplets high in total dissolved contaminants), noise, aesthetics, additional discharge of biocides in cooling tower blowdown, and additional solid waste generated as cooling tower basin sludge.

Many of the environmental impacts identified above are not as significant at plants where cooling towers have been designed and built as part of the original installation. This conclusion might not hold true if a large number of new cooling towers were installed as retrofits. Many of the plants that currently operate under $\$ 316(a)$ variances are older plants located in or near urban or suburban areas. Environmental impacts like drift or noise, which are mitigated by the large buffer zones around plants in rural locations, could present serious problems for urban locations. Freezing or fogging from cooling tower plumes could present a safety hazard.

The water consumption issue may be the most critical concern for a retrofitted cooling tower. If a plant is designed to consume a certain volume of water through evaporation, then that volume is factored in from the time a plant is built. However, if a cooling tower is added later, adequate water resources may not be available to accommodate the increased fresh water demand.

\section{Discussion}

\section{Regulatory Agency Must Be Satisfied that 316(a) Variance is Protective}

Although potential impacts can be associated with discharges permitted under §316(a) variances, regulatory agencies have the responsibility to ensure that the impacts are minimal or nonexistent. A $\S 316$ (a) variance is not trivially granted. To receive the variance, the discharger must demonstrate to the satisfaction of the regulatory agency that a discharge that exceeds the otherwise applicable thermal requirements will still protect a balanced, indigenous population in and on the receiving water. The effort required to make this case varies greatly, depending on state requirements and the site-specific potential for impacts. Typically the demonstration involves extensive evaluation of potential impacts and characterization of local aquatic populations. A regulatory agency can reject a demonstration or ask the discharger to study certain issues in more detail.

In 1992, the U.S. Environmental Protection Agency (EPA) evaluated the effectiveness of the $\$ 316(a)$ 
variance program. EPA found that for the majority of facilities, impacts from thermal effluent have not been found to be large or permanent. Several cases in which severe problems were found may have been the result of inadequate permit limits, rather than facility noncompliance with permit limitations?

Considering the oversight authority provided to regulatory agencies, the $\$ 316$ (a) variance program represents an "environmentally safe" form of economic incentive for thermal dischargers. The use of \$316(a) and other types of CWA variances can greatly reduce the cost to dischargers (and concomitantly, ratepayers) without increasing the risk to the environment beyond acceptable levels ${ }^{10}$.

\section{Other Affected Industries}

The steam electric power industry is the primary industrial sector that would be affected by a 1,000 -foot mixing zone limit, but other industries that use large volumes of water for cooling (e.g., steel, aluminum, paper, and cement manufacturing industries and waste-to-energy facilities) might also be affected. Impacts of the proposed mixing zone restrictions on these other industries were not estimated. The $\$ 316$ (a) variance is used almost exclusively by the power industry. Consequently, loss of the variance would have relatively little impact on other industrial sectors.

\section{Components of H.R. 961 That Might Affect Thermal Discharge Requirements}

H.R. 961 proposes many changes that could result in less stringent water pollution controls. Several of these are directly relevant to thermal discharge requirements.

Thermal Discharges. \$412 states that a municipal utility that discharges into the Upper Greater Miami River, Ohio, shall not be required to construct a cooling tower or operate under a thermal management plan unless:

"(1) the Administrator or the State of Ohio determines based on scientific evidence that such discharges result in harm to aquatic life; or (2) the municipal utility has applied for and been denied a thermal discharge variance under section 316(a) of such Act."

This language applies solely to municipal utilities located in one river segment, but it could set a precedent for future thermal discharge controls.

Mixing Zones. $§ 303(c)$ reaffirms the validity of mixing zones as follows:

"Nothing in this Act shall be construed to authorize the Administrator to prohibit or discontinue mixing zones established by any State for any pollutant or class of pollutants."

This statement clearly indicates that mixing zones should be allowed, but does not address the issue of mixing zone size or shape.

Consideration of Costs and Benefits. Water quality standards presently do not reflect economics. $\$ 303$ emphasizes that costs associated with any new standard must be reasonably related to the potential benefits that would result from implementing the new standards: 
"No water quality standard shall be established under this subsection where there is no reasonable relationship between the costs and anticipated benefits of attaining such standard."

$\$ 324$ requires a cost/benefit demonstration certifying that the requirement or guidance maximizes net benefits to society prior to issuance of any standard, effluent limitation, guidance, or other regulatory requirement. This section does not apply to water quality criteria or water quality-based standards. Thus, issuance of individual permit thermal limits or state thermal standards would not require such a demonstration, but general changes to thermal discharge requirements would obviate a demonstration. Several other broader risk-based bills are presently being considered by Congress.

\section{Conclusions}

A 1991 Senate bill, S. 1081, which would have prohibited $\$ 316$ (a) variances and restricted thermal mixing zones to 1000 feet, was not passed by the 102nd Congress. Although CWA reauthorization legislation introduced subsequently does not propose prohibiting $\$ 316(\mathrm{a})$ variances or restricting thermal mixing zones, it remains unclear how Congress will ultimately deal with thermal discharge issues. Until Congress has formally reauthorized the CWA, the potential for changes to the thermal requirements remains.

- Based on data collected from a large sample of power companies representing different geographic regions, most plants currently operating under a $\$ 316($ a) variance could not meet thermal standards without the variance and most plants using once-through cooling systems could not meet thermal standards within a 1000-foot mixing zone. The estimated cost to retrofit cooling towers and diffusers at existing power plants would range from \$21.4 billion to 24.4 billion. Owners of the retrofitted plants would need to spend an estimated $\$ 10$ billion to 18.4 billion in additional fuel costs and from $\$ 1.2$ to 5.3 billion to construct additional generating capacity to overcome the energy penalty.

The $\S 316$ (a) variance program has not caused significant environmental degradation and has resulted in considerable cost savings to ratepayers, yet deletion of the variance would have a large negative economic impact on the power industry. The magnitude of the estimated costs of losing the $\$ 316$ (a) variance is similar to the 1993 net electric operating income for major U.S. investor-owned electric utilities $(\$ 30.2 \text { billion })^{11}$. There appears to be little justification for deleting the $\S 316(\mathrm{a})$ variance.

- Any attempt to place statutory restrictions on thermal mixing zones would result in a very large cost to the power industry and perhaps to other industries as well. Policymakers should give careful consideration to these costs, in addition to the increased air emissions, solid wastes, and water evaporation attributable to cooling towers and diffusers, before adopting any national thermal mixing zone restrictions. The potential benefits of a 1,000 -foot or smaller mixing zone have not been widely discussed. Unless the potential benefits are believed to be commensurate with the large cost, little justification exists for limiting thermal mixing zones to 1,000 feet from the point of discharge. 


\section{Acknowledgements}

This work was sponsored by the U.S. Department of Energy, Office of Policy under Contract W-31-109Eng-38. C. Richard Bozek of Edison Electric Institute and Kristy A.N. Bulleit and Steven J. Koorse of Hunton \& Williams (representing the Utility Water Act Group) were instrumental in coordinating data submissions and industry review of the draft reports.

\section{References}

1. Impact on the Steam Electric Power Industry of Deleting Section 316(a) of the Clean Water Act: Capital Costs. Argonne, IL: Argonne National Laboratory, January 1993. ANL/EAIS-4

2. Impact on the Steam Electric Power Industry of Deleting Section 316(a) of the Clean Water Act: Energy and Environmental Impacts. Argonne, IL: Argonne National Laboratory, January 1993. ANL/EAIS-5.

3. Impact of a 1,000-Foot Thermal Mixing Zone on the Steam Electric Power Industry. Argonne, IL: Argonne National Laboratory, April 1994, ANL/EAD/TM-15.

4. Edison Electric Institute. Power Statistics Database, Washington, DC: Utility Data Institute, 1993.

5. Evaluation of the Potential Costs and Environmental Impacts of Retrofitting Cooling Towers on Existing Steam Electric Power Plants That Have Obtained Variances under Section 316(a) of the Clean Water Act, Washington, DC: Edison Electric Institute, April 1992.

6. Thermal Control Cost Factors. Washington, DC: Utility Water Act Group, 1978.

7. An Evaluation of Integrated-Gasification-Combined-Cycle and Pulverized-Coal-Fired Steam Plants, Palo Alto, CA: Electric Power Research Institute, 1988, EPRI AP-5950.

8. TAG Technical Assessment Guide, Electrical Supply - 1989, Palo Alto, CA: Electric Power Research Institute, EPRI P-6587-L, Vol. 1, Rev. 6, 1989.

9. U.S. Environmental Protection Agency. Review of Water Quality Standards, Permit Limitations, and Variances for Thermal Discharges at Power Plants, Washington, DC, October 1992, EPA 831-R92001.

10. Veil, J.A., "Economic Incentives for Clean Water", Water Environ. \& Tech. Vol. 5, No. 8, p. 25 (1993).

11. U.S. Department of Energy, Energy Information Administration. Financial Statistics of Major U.S. Investor-Owned Electric Utilities, Washington, DC, January 1995, DOE/EIA0437(93)/1, p.9. 